\title{
The Application of Salutogenesis to Correctional Officers in Corrections Settings
}

\author{
Robert A. Henning, Zandra M. Zweber, Andrea M. Bizarro, \\ Timothy Bauerle, Diana C. Tubbs, and David Reeves
}

\section{Introduction}

Correctional institutions are typically harsh environments for both corrections workers and the inmates who have been incarcerated. There is a paucity of literature on how to design prisons to be health promoting, and what is there largely focuses on behavioral and environmental approaches to benefit the health of inmates with little reference to salutogenesis (Dilani, 2001; Woodall, de Viggiani, Dixey, $\&$ South, 2014). Thus, this chapter introduces the emerging literature on salutogenesis in corrections workers, mainly coming out of the Center for the Promotion of Health in the New England Workplace (CPH-NEW, 2015), one of four centers of excellence supported by the Total Worker Health ${ }^{\circledR}$ program of the National Institute for Occupational Safety and Health in the United States (NIOSH, 2016).

In 2006, CPH-NEW received a request from union leaders in a state corrections system for help in addressing serious health problems being experienced by correctional officers and supervisors and hence sought out new field sites at which to conduct research-to-practice studies on integrated health protection and promotion programs. After determining there was a lack of prior research in this area, CPH-NEW conducted field studies at two matched correctional institutions with the overall goal of assessing if a

R.A. Henning, Ph.D., C.P.E. $(\bowtie)$ • Z.M. Zweber, Ph.D. • A.M. Bizarro, Ph.D. • T. Bauerle, Ph.D. • D.C. Tubbs, B.A.

Department of Psychological Sciences, University of Connecticut, Storrs, CT, USA

The Center for the Promotion of Health in the New England Workplace, University of Connecticut and University of Massachusetts Lowell, USA

e-mail: robert.henning@uconn.edu; zandra.zweber@gmail.com;

Andrea.bizarro@uconn.edu; tim.bauerle@uconn.edu; diana.

tubbs@uconn.edu

D. Reeves, Ph.D.

Sirota Consulting, Purchase, New York, NY, USA

e-mail: dreeves@sirota.com program that engaged correctional officers in the participatory design of workplace interventions would be more effective than a conventional program in which interventions are introduced in a top-down manner by health professionals. Through interactions with union leaders, corrections staff, and management for this project, $\mathrm{CPH}-\mathrm{NEW}$ researchers have gained a better understanding of the many challenges corrections workers face in this difficult work environment (Morse, Dussetschleger, Warren, \& Cherniack, 2011).

Correctional officers have one of the most stressful jobs in our society (Summerlin et al., 2010) yet have been largely neglected in occupational safety and health research. Chronic stress is linked to many negative health effects including cardiovascular disease (McCraty et al., 2009), and so it should not be surprising that correctional officers are at increased risk for this disease (Harenstam, Palm, \& Theorell, 1988). Rapid increases in musculoskeletal disorders among correction officers have also been linked to psychosocial exposures, including decision latitude (control), psychological demands, supervisor support, and coworker support (Warren, Dussetschleger, Punnett, \& Cherniack, 2015). Additionally, nearly one in four correctional officers fit the criteria for posttraumatic stress disorder (PTSD) (Spinaris, Denhof, \& Kellaway, 2012), and it was estimated that correctional officers suffer from suicide rates nearly triple of those observed among the general population and in other related occupations such as police officers (State of New Jersey \& Governor's Task Force on Police Suicide, 2009). High numbers of workers compensation claims and sick days are also common in corrections, with one study reporting that correctional officers in the state of New York have an absenteeism rate three times higher than the average rate of all other occupations (Schaufeli \& Peeters, 2000). One of the more sobering statistics is that actuarial tables indicate a 12-15-year life expectancy gap between correctional officers and the general population (Cheek, 1984; Commission on Safety and Abuse in America's Prisons, 2005). 
The above evidence is particularly alarming because young adults usually join this workforce in above-average health after meeting physical fitness standards as part of academy selection and training, and because their health benefits often includes access to such things as employee assistance programs that provide support beyond primary and secondary medical care. In general, the evidence suggests that conventional compensatory approaches to occupational health which focus on reducing or eliminating recognized health risks, as well as reducing the impact of health problems, have not been fully effective in protecting and promoting the health of correctional officers. New approaches need to be considered.

In this chapter, we first describe some of the root causes of health problems in corrections by reporting findings that emerged from a focus group study on correctional officer stress (Bauerle, Zandra, Bizarro, Henning, \& Roberts, 2013). This also serves to highlight why Antonovsky's (1979) theory of human perception, sense of coherence, is so relevant to correctional officers who must cope with the challenging stress of their job. Existing research is then reviewed that provides evidence for the potential role that individual sense of coherence and salutogenic health promotion programs could play in mitigating the effects of workplace stress. A set of recommendations are then made for planning salutogenic interventions in corrections, including assessing the organizational health climate and correctional officers' perceptions of the health-promoting qualities of their workplace. We then go on to describe the salutogenic aspects of a programmatic approach CPH-NEW has used successfully in corrections and elsewhere to engage front-line employees in the design of workplace interventions to benefit worker health protection and promotion. We also describe an officer-led health mentoring program that is currently being implemented by CPH-NEW, and how it was shaped in part, by application of salutogenic principles. We end this chapter by discussing future research needs and application areas.

\section{Sources of Officer Stress in Corrections Settings}

Of the many health, safety, and well-being issues that pertain to work in corrections, job stress is one of the most salient and pervasive (Neveu, 2007; Schaufeli \& Peeters, 2000; Whitehead \& Lindquist, 1986). Although the need for interventions to address job stress in corrections is undeniable, part of the challenge in pursuing successful interventions stems from the multifaceted nature of job stressors specific to corrections. This makes it challenging for researchers and organizations to decide which stressors to target with an intervention. Also, field research by CPHNEW has shown that correctional officers tend to under- report stress levels, as evidenced by physiological data that indicate high stress exposures, such as hypertension (Morse et al., 2011). This finding is just one example of how challenging it might be to establish and maintain a salutogenic approach in this underserved population of workers. Adding to this challenge, correctional officers tend to be quite cynical about their organization and about organizational change in general (Schaufeli \& Peeters, 2000).

Research on job stress is very limited in this population, and so a structured focus group study was conducted to investigate its sources (Bauerle et al., 2013). Initial validation efforts of the focus group script with union leaders in corrections, however, revealed that mainstream definitions of stress were not an appropriate fit for describing how stress is experienced among correctional officers. Therefore, correctional officers participating in these focus groups were first asked to define job stress collaboratively. The stress definition that emerged in each focus group then served during the remainder of that focus group meeting as the basis for specific questions concerning sources of stress.

We found that the many sources of stress for correctional officers are not only very complex and interconnected, but are also deeply ingrained in the culture of corrections work and the way this work is structured. For example, a common misconception is that interacting with inmates is the most significant source of occupational stress for correctional officers due to the dangerous and unpredictable nature of inmate behaviors and frequent contentious interactions with them. However, our research confirms previous findings that this is not the case (Whitehead \& Lindquist, 1986). Rather, various work organization factors, strict administrative oversight, and seemingly contradictory and rigid policies and procedures are reported as being more stressful to corrections workers than interacting with inmates. Other major sources of stress for correctional officers include concerns about security and work/family imbalance (Morse et al., 2011).

\section{Need for and Conceptualization of Salutogenic Interventions}

Consideration of the organizational context for any intervention is of paramount importance to its success. Ultimately, the health climate of a correctional institution may provide the best global estimate of the strength of salutogenesis in this workplace as well as organizational readiness for salutogenic interventions. Organizational health climate itself can be conceptualized as salutogenic in nature because of its focus on positive health norms within an organization. Organizational health climate has been defined in our research as "employee perceptions of active support from upper management as well as supervisors and coworkers for 
the physical and psychological wellbeing of employees" (Zweber, Henning, \& Magley, 2016). A healthy organization is one that focuses not only on the success of the organization but also on employee health and well-being (Sauter, Murphy, \& Hurrell, 1990). Organizational health climate is also considered a key component of a healthy organization.

From a salutogenic and Total Worker Health ${ }^{\circledR}$ (NIOSH, 2016) perspective, the organizational health climate of a healthy organization reflects a set of norms among individuals in this organization that are based on positive health attitudes and behaviors. An organization with a robust health climate will have positive health norms among employees in addition to feedback and feedforward control systems in place to maintain these norms. These systems enable organizations to not only respond to employee health needs in a compensatory manner but also to be proactive and prevent health issues from occurring in the first place (Henning \& Reeves, 2013).

Although efforts can and should continue to identify and reduce work stressors found in corrections, altogether eliminating these stressors may not be possible. Working in correctional institutions will continue to be dangerous, and a hierarchical organization with a chain of command is necessary to ensure adherence to critical safety protocols and procedures. Consequently, conventional workplace intervention approaches that focus solely on reducing or eliminating existing stressors as risk factors to health are not likely to be fully effective in this particular work environment.

A complementary approach to risk reduction efforts, consistent with salutogenic principles being advocated here, contributes to health improvement by strengthening correctional officers' resources for handling stress through the participatory design of workplace interventions that address sources of stress as well as other health and safety concerns. This suggests that departments of correction that implement salutogenic policies and practices in support of empowering and engaging correction officers in this manner can expect improved employee health outcomes compared to those that implement policies and practices limited to only addressing the pathogenic aspects of health. Beyond the salutogenic benefits to correctional officers from simply being involved in these participatory design efforts, any resulting workplace interventions are also more likely to be salutogenic in nature, as explained below.

\section{The Potential for Sense of Coherence to Moderate Stress in Corrections}

CPH-NEW has also focused on the well-established salutogenic theory of sense of coherence in relation to how correctional officers respond to stressful situations.
Antonovsky (1979) originally conceived of sense of coherence within the salutogenic framework to help explain why some individuals were able to survive challenging conditions while others floundered. Individuals with high sense of coherence gather and utilize internal and external resources to manage stressful or challenging situations by perceiving and experiencing these situations as meaningful, manageable, and comprehensible (Antonovsky, 1987b). Therefore, the sense of coherence construct appears to be well suited to assessing correctional officer resilience in stressful situations given the unavoidable challenging and life-threatening conditions these workers face.

The importance of sense of coherence for workers has been demonstrated in many other work settings. Personal tension resulting from stressful events is inevitable regardless of socioeconomic status or cultural background, and all individuals experience breakdown, or stress, as a result of unsuccessfully managing moments of strain (Antonovsky, 1979). Furthermore, even though Antonovsky (1979) originally theorized that sense of coherence is relatively stable after the age of 30 , he later acknowledged that an individual's first experiences in a work environment could be a key feature in shaping an individual's sense of coherence, and ultimately included an individual's work environment in his model of how to promote sense of coherence (Antonovsky, 1987a; 1996). Therefore, the protective benefits of sense of coherence identified in other work contexts will most likely apply to correctional officers. Correctional officers with a strong sense of coherence would be expected to be more resilient and better able to handle stressors which may otherwise be perceived as either overwhelming or unmanageable.

When Antonovsky laid out his new model of salutogenesis in which job characteristics affect the three factors of sense of coherence (comprehensibility, manageability, and meaningfulness) individually (1987b), comprehensibility was theorized to be affected by the job security and climate within the workplace. Without job security and high-quality communication, employees can begin to feel confused and uncertain about many aspects of the organization they work in, and these uncertainties can be expected to undermine the comprehensibility of their work environment. Therefore, some specific ways of promoting salutogenesis in the corrections environment could include improving the quality and effectiveness of supervisor and coworker communications as well as increasing correctional officer involvement in organizational decision making. Interventions like these could directly reduce correctional officers' strain by improving their ability to perceive stressful events in corrections as more meaningful, manageable, and comprehensible (Henning \& Reeves, 2013).

The methods for promoting salutogenesis in the workplace mentioned thus far suggest that workplace policies and 
practices are important factors to consider in correctional officers' experiences of job stress. However in the corrections environment, the development of a positive organizational health climate might be particularly challenging due to certain deeply rooted attitudes, perceptions, and norms found in this highly structured workplace and work organization. For one, it is typical for both male and female correctional officers to openly portray a "tough exterior." Consequently if caring about health and wellness is viewed as a sign of personal weakness, then correctional officers will be less likely to engage in this behavior. On the other hand, correctional officers generally experience a strong sense of camaraderie because each officer can depend on other officers to "have his/her back." This means that correctional officers are committed to doing everything possible to provide immediate assistance whenever a fellow correctional officer is threatened or attacked by inmates. This same camaraderie could also help unite officers in the creation of a positive health norm. Additionally, there is a general readiness among correctional officers to take action to improve or maintain their health because many are well aware that their fellow officers sometimes die suddenly just before or shortly after reaching retirement age, in some cases after only 20 years of service. This readiness for change can contribute to the effectiveness of salutogenic workplace interventions and their impact on organizational health climate and correctional officer sense of coherence.

\section{Descriptive Research}

Beyond the research on sense of coherence and correctional officers conducted by $\mathrm{CPH}-\mathrm{NEW}$, research investigating the influence of salutogenesis and sense of coherence on job-specific strains and also physical and mental health has grown in recent years. For example, individuals with high sense of coherence reported lower levels of emotional exhaustion and occupational disengagement related to job strain in Sweden (Söderfeldt, Söderfeldt, Ohlson, Theorell, $\&$ Jones, 2000), and nurses with a strong sense of coherence demonstrated positive affect following stressful task interruptions in Hong Kong (Shiu, 1998). Furthermore, sense of coherence has demonstrated a buffering effect on the negative impact of work strain on mental health in several diverse samples including: Israeli social workers (Gilbar, 1998), German healthcare workers (Hoge \& Bussing, 2004), Lithuanian nurses (Malinauskiene et al., 2009), and real estate brokers in Western Australia (Love et al., 2011).

In longitudinal studies, one 3-year cross-lagged study of Finnish managers found support for the positive influence of employee sense of coherence on developing organizational climate (Feldt et al., 2004). Feldt and colleagues (2000) and also Rothmann, Steyn, and Mostert (2005) found that increases in the quality of supervisor-subordinate relationships resulted in increases in employees' sense of coherence in samples of 219 Finnish employees from four separate organizations and 215 South African employees of an electrical company, respectively. Albertsen, Nielsen, and Borg (2001) found in a study of Danish employees that increased coworker support and involvement in meaningful decisions, both of which could be fostered through a salutogenic intervention, were positively related to an individual's sense of coherence.

Although correctional officer sense of coherence is rarely assessed in the literature, one study investigated the potential beneficial effects of sense of coherence on uniformed male officers in Poland (Ogińska-Bulik, 2005). In the sample of 330 uniformed male officers, which included policemen, firefighters, correctional officers, security guards, and city guards, correctional officers had the highest sense of coherence, the lowest level of job stress and also the best state of health. The relationship between sense of coherence and perceived job stress in the overall sample of uniformed officers indicated that sense of coherence matters in regard to how officers assess various situations as being either stressful or not stressful, suggesting that sense of coherence could also play a major role in corrections in regard to how correctional officers cope with stressful situations.

Each of the above studies lends support to the working assumption that salutogenic interventions that impact organizational climate in corrections can result in an increase in employee sense of coherence because the same organizational factors that change to benefit organizational health climate can also contribute to employees' sense of coherence. Given the conceptualization of organizational health climate as an important component of healthy organizations, increased sense of coherence among officers could also contribute to a healthier organization. Together, the above studies provide some support for a reciprocal relationship between a desirable organizational climate and high employee sense of coherence, and show potential for promoting both within departments of correction to significantly benefit employee well-being.

\section{Intervention Research: Measures of Salutogenic Work and Organization}

In order to perform meaningful research on salutogenic interventions, it is important to have validated measures of the salutogenic change and outcomes such as an improved organizational health climate. In order to measure organizational health climate in a way that such interventions can be better planned and tracked, the Multi-faceted Organizational Health Climate Assessment (MOHCA) scale was developed 
which separates health climate into three organizational levels: workgroup, supervisor, and organization (Zweber et al., 2016). We posit that this scale can be used effectively as a diagnostic tool to address salutogenic needs at each organizational level within corrections. The facets of this scale can be used to assess whether there are strengths or weaknesses in regard to the norm for health and health promotion at the work group, supervisor, or organizational levels. Identifying any potential weaknesses, such as the lack of support and encouragement from supervisors for employee involvement in health promotion programs available in the organization, could be used to help target-specific workplace health interventions to benefit organizational health climate and the sense of coherence of correctional officers in general.

In regard to the measurement of workplace factors related to salutogenic interventions, there is also a newly developed work-related sense of coherence scale (Work-SoC) which assesses "the perceived comprehensibility, manageability and meaningfulness of an individual's current work situation" (Vogt, Jenny, \& Bauer, 2013). Using this scale to assess a correctional officer's perception of the potential health-promoting qualities of his/her current work situation could help target-specific characteristics of the working environment (any work-related structures and processes) for salutogenic interventions. For example, if many correctional officers rate their current jobs and work situations as unmanageable, interventions could increase the involvement of correctional officers in decision-making activities that would significantly impact their current work situations.

If it is possible for upper management to evaluate the salutogenic orientation of their workplace via organizational health climate, and also employees' perceived comprehensibility, manageability, and meaningfulness of their current work situations, it may also be possible to identify deficiencies that are most salient to correctional officers at a given correctional institution. Scores on the MOHCA and Work-SoC assessments described above can therefore serve as a starting point in setting priority areas for salutogenic workplace interventions.

\section{Participatory Design of Workplace Interventions}

Once workplace deficiencies have been identified, it would be best if correctional officers are able to engage in planning interventions to correct these deficiencies. This is because their direct involvement in the planning and design of interventions can benefit their sense of coherence according to the model put forth by Antonovsky (1987a). Aspects of the workplace that can affect health and well-being would immediately become more comprehensible and manageable if employees are provided with some training on ergonomics and health promotion principles prior to engaging in intervention design activities. It is also inherently meaningful for employees to be involved in intervention planning efforts that will benefit their own health and safety as well as that of fellow correctional officers and their families. In addition to influencing comprehensibility and manageability, participation in decision making is known to be a key job design characteristic for individuals to find meaning in their work (Albertsen et al., 2001; Sagy \& Antonovsky, 2000).

Thus, fostering collaboration and shared decision-making activities between management and front-line employees during intervention planning efforts like these, which would include working with lieutenants, captains, and counselor supervisors within corrections (Reeves, Walsh, Tuller, \& Magley, 2012), has the potential to benefit all three dimensions of sense of coherence for those involved.

Researchers are increasingly studying whether programmatic approaches in various settings (i.e., residential, educational, clinical, and work) can impact individual sense of coherence with positive results (Bauer \& Jenny, 2007; Kähönen, Näätänen, Tolvanen, \& Salmela-Aro, 2012). A program which supports employees being regularly involved in the participatory design of workplace interventions has been developed by CPH-NEW researchers (Henning, Warren, Robertson, Faghri, \& Cherniack, 2009). This programmatic approach for supporting continuous improvement of employee health protection and health promotion has been tested at two correctional institutions. Modeled after participatory ergonomics (PE) programs for continuous improvement (e.g., Haims \& Carayon, 1998), and also incorporating health promotion (HP) principles, the resulting, integrated "PExHP" program (CPH-NEW, 2016) can provide a number of salutogenic benefits (Henning \& Reeves, 2013).

A PExHP program consists of a "design team" of 5-10 front-line workers who design workplace interventions, and also a program steering committee that provides general program oversight and chooses which workplace interventions to implement. The design team first receives training on how to apply principles of participatory ergonomics and health promotion, then with the help of a program facilitator and without any of their supervisors present, the design team prioritizes health/safety issues/concerns and engages in intervention planning efforts. A set of intervention proposals is then presented to the steering committee for possible implementation. In many cases, the design team can also assist with both their implementation and evaluation. The planning and design cycle then repeats, with the design team focusing on the next high-priority health/safety issue/ concern for continuous improvement of workplace health and safety to assure program sustainability.

This structured process for planning interventions within PExHP programs has been developed and tested through use 
of the Intervention Design and Analysis Scorecard, or IDEAS Tool (Robertson et al., 2013, 2015). The IDEAS Tool further empowers front-line employees in the intervention planning process by providing step-by-step guides for how to first identify root causes of problems/concerns (that can be either pathogenic or salutogenic in nature), and then to develop intervention ideas along with a business case for their implementation that the steering committee and upper management can then review and often support. This structured participatory approach to intervention planning within PExHP programs can contribute to meaningful ownership of the interventions by both management and frontline employees, something that is known to greatly contribute to the success of an intervention when it is eventually implemented (Brown, 2002; Cherniack et al., 2016; Henning et al., 2009).

The workplace interventions that were approved and implemented by site steering committees in the PExHP programs in corrections addressed a wide range of health/ safety issues/concerns, and in accordance with Total Worker Health principles, consisted of a combination of behavioral/ lifestyle changes and changes to the workplace in order to more fully benefit both health protection and promotion (Robertson et al., 2013; Ferraro, Faghri, Henning, \& Cherniack, 2013). At one correctional institution for example, the combined design team and steering committee organized a health fair with themes most relevant to correctional officer well-being, such as how to establish healthy sleep patterns when working third shift. Upper management arranged for a rotation schedule that would relieve each correctional officer from his/her duties long enough to attend this event, demonstrating the top-down support from management that is essential to improving organizational health climate as defined earlier.

PExHP programs are expected to contribute to salutogenesis in corrections in several ways. As reviewed by Henning and Reeves (2013), comprehensibility in Antonovsky's model was theorized to be affected by the climate within the workplace, which is highly dependent on high-quality communications. Albertsen et al. (2001) found that support from coworkers was related to increases in sense of coherence, and PExHP programs provide this support by helping front-line workers address their health/ safety issues/concerns together as well as jointly with mid-level supervisors and upper management. Workplace climate is also benefited by managerial commitment to the PExHP program because PExHP programs support a continuous improvement process with employee involvement, acknowledgment of employee health/safety issues/concerns, and increased collaboration with management within a structured intervention planning approach that improves management-employee relations on health-related matters (Henning \& Reeves, 2013).
The effectiveness of a PExHP program from the perspective of the employee participants on the design team can also be assessed, supporting efforts for continuous improvement of the program itself (Matthews, Gallus, \& Henning, 2011). It is also possible within PExHP programs for an organization to require that each workplace intervention has a salutogenic impact in addition to the conventional evaluation criteria of impact/scope, short and long-term health and safety benefits/effectiveness, resources/cost, and barriers/ obstacles to implementation (Henning \& Reeves, 2013). For example, an expected salutogenic impact could be an aspect of Work-SOC such as the need for jobs and work situations to become more structured, which would then be considered along with the conventional evaluation criteria when rating each potential intervention activity. Those intervention activities ranking high in aspects or dimensions of Work-SOC would be more likely to be chosen for implementation by the PExHP program steering committee.

\section{Coworker Mentoring as a Salutogenic Intervention}

CPH-NEW is currently conducting research on one other programmatic intervention approach in corrections that has a salutogenic focus; a health mentoring program designed to protect and promote the health of incoming correctional officers. Based on empirical evidence collected in $\mathrm{CPH}-$ NEW studies, the health of these new officer cadets is highly vulnerable to the detrimental effects of job stress during their first years of service. By pairing veteran correctional officers (the mentors) and new officers (the protégés), a relationship is formed through regular informal meetings that provides opportunities for new officers to discuss problems they face as a corrections worker, and to receive support and guidance from an experienced officer.

The health mentoring program is designed, in part, to improve cadet resiliency, and so provides another opportunity to apply salutogenic principles in this challenging work environment. In addition to helping buffer the impact of stressors on new officers' health in their first years of service, improving the sense of coherence of these officers also has the potential to benefit their health and well-being for as long as they work in corrections according to Antonovsky's conceptualization that individuals' environments can affect their level of sense of coherence (Antonovsky, 1987a; 1996).

The question of whether sense of coherence in the workplace is an enduring trait, or is an orientation that is influenced by one's environment (Vanndrager \& Koelen, 2013; Vogt et al., 2013), is one for which the mentor project hopes to determine. And although mentoring is a fairly common intervention that has been studied in many settings, particularly the workplace (Eby, Allen, Evans, Ng, \& 
DuBois, 2008), we are not aware of any published study examining the relationship between mentoring initiatives and sense of coherence in the workplace.

Several components of the CPH-NEW health mentoring program were guided by a salutogenic perspective. A primary concern for the research team was that being in the program needed to be experienced as manageable by the mentors who would be involved on a volunteer basis. Inasmuch as program manageability would be impacted by the effectiveness of the mentor-protégé relationships, mentors were provided with special training regarding their role as a mentor. Given the rigid hierarchical nature of corrections systems, establishing an appropriate mentoring role is somewhat challenging because officers were previously not allowed to deviate from the existing personnel policies and procedures regarding employee interactions.

Therefore, a participatory design approach was initially adopted involving corrections staff, union leaders and the $\mathrm{CPH}-\mathrm{NEW}$ research team to carefully define the role of a correctional officer mentor.

Another salutogenic consideration regarding the structure of the health mentoring program was the perceived degree of comprehensibility of the program for both mentors and protégés. In part because the health mentoring program was unprecedented at the study sites, a participatory design approach was initially adopted to help promote program comprehensibility. The first meeting of the mentor and his/her protégé was used to set expectations for both parties, and as a means to establish clarity and understanding on what the mentor-protégé interactions might entail. Initially, the mentor-protégé relationship is likely to be somewhat ambiguous but it can be later clarified to become more predictable and also more comprehensible to both parties given the way that this mentor program has been structured.

Finally, the health mentoring program was specifically designed to support mentor-protégé relationships (Vanndrager \& Koelen, 2013). Protégés are therefore expected to increase their sense of coherence because they will experience increased social support; that is, the degree to which they perceive that other employees care about their well-being on the job through positive forms of social interaction (Kossek, Pichler, Bodner, \& Hammer, 2011). This is particularly valuable in a corrections environment where there is a general expectation for new officers to be tough, and where there is disapproval for any new officer expressing weakness. Similarly, social support in the mentor program lends itself to a meaningful experience for the protégés by creating a sense of belonging (Vanndrager \& Koelen, 2013).

For mentors, the act of mentoring itself has significance because it affects the degree to which they perceive their job activities as having a positive impact on other people. These aspects of the health mentoring program are expected to promote salutogenesis in the workplace and also support the development of a healthy organization.

\section{Discussion}

Salutogenic approaches to improving the health and wellbeing of correctional officers show great potential to help these public service officers become more resilient and capable of handling the many stressors they encounter on a daily basis. Salutogenic approaches for developing individual sense of coherence and improving organizational health climate can also help balance the pathogenic focus that dominates most health protection and health promotion programs that currently exist in corrections and elsewhere.

Regular assessment of organizational health climate could help corrections organizations verify that acceptable norms for salutogenesis have been established at the coworker, supervisor, and organizational levels. In addition, the Work-SoC Scale could be used to regularly assess correctional officer's perceptions of the potential healthpromoting qualities of their workplace.

In conjunction with regular organizational and workplace assessments, engaging correctional officers in a programmatic approach for planning workplace interventions on a continuous basis is also recommended. Correctional officer sense of coherence can be benefited by the specialized ergonomics and health promotion training that correctional officers receive prior to planning workplace interventions on a design team, and by their engagement in the process of identifying and prioritizing health problems and concerns (knowledgeability), and collaborating with upper management (manageability and meaningfulness).

It is also possible for organizations to set salutogenic standards for workplace interventions as part of their PExHP program (Henning \& Reeves, 2013). An officer-toofficer health mentoring program has the potential to benefit new correctional officers' sense of coherence in the first years of their career when they appear to be most vulnerable to loss of good health, and during a period in which their work experiences may have the largest impact on the development of their sense of coherence. This health mentoring program can also be expected to strengthen the sense of coherence of the correction officer mentors (meaningfulness).

\section{Implications for Salutogenesis Research}

Further research is needed to examine barriers to successful salutogenic interventions in corrections, and also to determine how to overcome them. For example, a better 
understanding of the determinants of the workplace culture in corrections may suggest a means to get past the external toughness that is often portrayed by correction officers, even when they are distressed and experiencing job burnout. And although we highlighted the potential for a reciprocal relationship between organizational health climate and correctional officer sense of coherence, empirical research is needed to examine the possibility that improved organizational health climate would contribute to the effectiveness of salutogenic interventions, and vice versa.

Longitudinal studies on the Work-SoC of correctional officers could reveal the extent that sense of coherence changes over time for individuals in this work sector, and could also shed light on the long-term sustainability of integrated participatory programs, such as PExHP program described earlier, and their impact on Work-SoC and sense of coherence. CPH-NEW only recently included the new Work-SoC scale developed by Vogt et al. (2013) in an All-Employee Survey, and so it is not yet possible to conduct longitudinal analyses to determine if Work-SoC changes over time. Efforts to validate the Work-SoC Scale for corrections workers may reveal the need for an adapted Work-SoC scale with items that are more specific to this work sector due to the peculiarities of corrections work. A sector-specific Work-SoC scale for corrections could perhaps be developed through participatory action research in which correctional officers would help define the key salutogenic aspects of this workplace.

The introduction of programmatic interventions is particularly challenging in corrections because of environmental constraints, strict adherence to policies and procedures, and the hierarchy of command and control described earlier. This places increased importance on gaining and maintaining internal sources of organizational support for any new initiative. In the case of the officer-led health mentoring program for example, we learned from separate focus groups conducted with mentors and mentees how crucial supervisory support was to program effectiveness. Help from supervisors was needed in scheduling regular sit-down meetings between mentors and their mentees at the very beginning of the mentoring process.

While instances where supervisory support was lacking could be considered a basic program training issue, another explanation is that supervisors withheld support for this program because they were unable to supervise the activities associated with mentoring that were necessarily conducted in private and remained confidential. This loss of a supervisory oversight can be characterized within a Behavioral Cybernetics model (Smith \& Smith, 1987) as interfering with the social-relational tracking opportunities that are normally available to supervisors for all of the activities their subordinates are involved in.
In order to compensate for the inability of supervisors to track mentoring activities and the developing mentor-mentee relationships directly, organizational communications about the social-relational tracking dynamics of mentoring may need to be considered as substitutes, and may also serve to promote the organizational learning (Haims \& Carayon, 1998) that is needed to establish the program. Possibilities here include periodically providing supervisors with examples of the salient topics being addressed when mentors and mentees meet privately, or to report officer health and well-being outcomes in order to demonstrate the value of psychosocial support gained through mentoring as a significant organizational innovation (Smith, 2002).

Another possibility is to regularly generate organizational communications about how a salutogenic program is evolving to meet organizational needs. Organizational communications like these in corrections may also serve to increase the number of stakeholders in these programs, a development with the potential to benefit program stability (Smith, Henning, Wade, \& Fisher, 2014) as well as longterm sustainability.

Sense of coherence was originally conceptualized by Antonovsky to occur at the level of the individual but the growing number of research studies on emergent group behaviors (e.g., Furniss, Back, Blandford, Hildebrandt, \& Broberg, 2011; McKendrick et al., 2014; Morgan, Fletcher, \& Sarkar, 2013) and "collective efficacy" (Coultas, Driskell, Burke, \& Salas, 2014) suggests the possibility that teams of workers could also possess a sense of coherence. If such a thing as "team sense of coherence" exists, it could play an important role in determining both team performance effectiveness and resilience. One implication for future research is that a new way of characterizing and assessing the three dimensions of sense of coherence at the team level would probably be needed because it is unlikely that team sense of coherence would be well represented by simply aggregating the sense of coherence of individual team members. The need for high-quality communication among team members, the extent that behaviors are coordinated among team members, and the degree to which team members support each other's health similar to what is assessed in the coworker dimension of MOHCA, may all play a role in establishing and maintaining team sense of coherence. Empirical research demonstrating the importance of team or group sense of coherence could help justify more comprehensive salutogenic interventions in the workplace, such as developing specific ways that teams can be efficiently trained or better organized to achieve a high level of sense of coherence.

The authors of this chapter claim no expertise regarding the psychology of inmates but can speculate that the application of salutogenic principles and approaches could benefit 
inmates in important ways. Salutogenic interventions and programs geared to younger inmates may be particularly effective in regard to increasing their sense of coherence. It has already been suggested that correctional environments could be made more salutogenic for inmates, making it is possible for them to find their situation more meaningful, comprehensible, and manageable, and thereby empowering them over the long term to change their behaviors and help reduce recidivism (Dilani, 2001).

Another possibility that could be explored is simultaneously implementing parallel salutogenic programs for inmates as well as correctional officers. For example, correctional officers may find it very meaningful to help design a program to strengthen the sense of coherence of inmates who they interact with regularly, thereby also benefiting the sense of coherence of correctional officers involved. Inmates with a strong sense of coherence are likely to be better at handling the stress of being in a correctional institution, which could reduce the number of incidents where their loss-of-control leads to violent behaviors that place correctional officers, other inmates, and themselves at serious risk of injury. Thus, implementation of parallel salutogenic programs in corrections has the potential to yield synergistic salutogenic benefits.

\section{Challenges for the Future}

There is a pressing need for more researchers in occupational health and safety to explore salutogenic approaches to benefit the sense of coherence and health and well-being of correctional officers because the many stressors these dedicated public service workers must face on a daily basis can have a devastating impact on the quality and length of their lives.

\begin{abstract}
Acknowledgments This work was supported by Grants No. U19-OH008857 and 5T01OH008610-09, and Contract No. 000HCCGE-2010-85721, from the National Institute for Occupational Safety and Health (NIOSH) at the Centers for Disease Control and Prevention in the United States of America. The contents of this article are solely the responsibility of the authors and do not necessarily represent the official views of NIOSH.
\end{abstract}

Open Access This chapter is distributed under the terms of the Creative Commons Attribution-Noncommercial 2.5 License (http:// creativecommons.org/licenses/by-nc/2.5/) which permits any noncommercial use, distribution, and reproduction in any medium, provided the original author(s) and source are credited.

The images or other third party material in this chapter are included in the work's Creative Commons license, unless indicated otherwise in the credit line; if such material is not included in the work's Creative Commons license and the respective action is not permitted by statutory regulation, users will need to obtain permission from the license holder to duplicate, adapt or reproduce the material.

\section{References}

Albertsen, K., Nielsen, M. L., \& Borg, V. (2001). The Danish psychosocial work environment and symptoms of stress: The main, mediating, and moderating role of sense of coherence. Work \& Stress, 15, 241-253.

Antonovsky, A. (1979). Health, stress and coping. San Francisco: Jossey-Bass.

Antonovsky, A. (1987a). Health promoting factors at work: The sense of coherence. In R. Kalimo, M. Eltatawi, \& C. Cooper (Eds.), PsychoSocial factors at work and their effects on health (pp. 153-167). Geneva: World Health Organization.

Antonovsky, A. (1987b). Unraveling the mystery of health. How people manage stress and stay well. San Francisco: Jossey-Bass.

Antonovsky, A. (1996). The salutogenic model as a theory to guide health promotion. Health Promotion International, 11(1), 11-18.

Bauer, G., \& Jenny, G. (2007). Development, implementation and dissemination of occupational health management (OHM): Putting salutogenesis into practice. In J. Houdmont \& S. McIntyre (Eds.), Occupational health psychology: European perspectives on research, education and practice. Dordrecht: Springer.

Bauerle, T. J., Zandra, Z., Bizarro, A., Henning, R. A., \& Roberts, R. (2013, May). Unique perspectives of job stress among correctional officers: A qualitative investigation. Poster presented at the biennial Work, Stress and Health Conference, Los Angeles.

Brown, O., Jr. (2002). Macroergonomic methods: Participation. In H. W. Hendrick \& B. M. Kleiner (Eds.), Macroergonomics: Theory, methods, and applications (pp. 25-44). Mahwah, NJ: Lawrence Erlbaum.

Center for the Promotion of Health in the New England Workplace (CPH-NEW). (2016). Center Co-Directors: Dr. Laura Punnett, University of Massachusetts Lowell, and Dr. Martin Cherniack, University of Connecticut. Retrieved May 23, 2016, from http:// www.uml.edu/Research/centers/CPH-NEW/

Cheek, F. (1984). Stress management for correctional officers and their families. College Park, MD: American Correctional Association.

Cherniack, M. G., Dussetschleger, J., Farr, D., El Ghaziri, M., Namazi, S., \& Henning, R. A. (2016). Participatory action research in corrections: The HITEC 2 program. Applied Ergonomics, 53, $169-180$

Commission on Safety and Abuse in America's Prisons. (2005, November 1-2). A look at the problems from the perspective of correctional officers. VERA Institute of Justice. Retrieved from http://www.vera.org.

Coultas, C. W., Driskell, T., Burke, C. S., \& Salas, E. (2014). A conceptual review of emergent state measurement: Current problems, future solutions. Small Group Research, 45(6), 671-703.

Dilani, A. (2001). Psychosocially supportive design-Scandinavian healthcare design. In A. Dilani (Ed.), Design and health-a health promoting approach on prison environments (pp. 5-151). Stockholm: AB Svensk Byggtjänst.

Eby, L. T., Allen, T. D., Evans, S. C., Ng, T., \& DuBois, D. L. (2008). Does mentoring matter? A multidisciplinary meta-analysis comparing mentored and non-mentored individuals. Journal of Vocational Behavior, 72, 254-267. doi:10.1016/j.jvb.2007.04.005.

Feldt, T., Kinnunen, U., \& Mauno, S. (2000). A mediational model of sense of coherence in the work context: A one-year follow-up study. Journal of Organizational Behavior, 21, 461-476.

Feldt, T., Kivimäki, M., Rantala, A., \& Tolvanen, A. (2004). Sense of coherence and work characteristics: A cross-lagged structural equation model among managers. Journal of Occupational and Organizational Psychology, 77, 323-342.

Ferraro, L., Faghri, P. D., Henning, R. A., \& Cherniack, M. (2013). Workplace-based participatory approach to weight loss for 
correctional employees. Journal of Occupational and Environmental Medicine, 55(2), 147-155.

Gilbar, O. (1998). Relationship between burnout and sense of coherence in health social workers. Social Work in Health Care, 26(3), 39-49. doi:10.1300/J010v26n03_03.

Furniss, D., Back, J., Blandford, A., Hildebrandt, M., \& Broberg, H. (2011). A resilience markers framework for small teams. Reliability Engineering and System Safety, 96, 2-10.

Haims, M. C., \& Carayon, P. (1998). Theory and practice for the implementation of "in-house" continuous improvement participatory ergonomics programs. Applied Ergonomics, 29, 461-472.

Harenstam, A., Palm, U.-B., \& Theorell, T. (1988). Stress, health and the working environment of Swedish prison staff. Work \& Stress, 2 , 281-290.

Henning, R. A., \& Reeves, D. W. (2013). An integrated health protection/promotion program supporting participatory ergonomics and salutogenic approaches in the design of workplace interventions. In G. Bauer \& J. Gregor (Eds.), Salutogenic organizations and change: The concepts behind organizational health intervention research (pp. 307-324). The Netherlands: Springer.

Henning, R. A., Warren, N., Robertson, M., Faghri, P., \& Cherniack, M. (2009). Workplace health promotion through participatory ergonomics: An integrated approach. Public Health Reports, 124(Suppl 1), 26-35.

Höge, T., \& Büssing, A. (2004). The impact of sense of coherence and negative affectivity on the work stressor-strain relationship. Journal of Occupational Health Psychology, 9(3), 195-205. doi:10. 1037/1076-8998.9.3.195.

Kähönen, K., Näätänen, P., Tolvanen, A., \& Salmela-Aro, K. (2012). Development of sense of coherence during two group interventions. Scandinavian Journal of Psychology, 53, 523-527.

Kossek, E. E., Pichler, S., Bodner, T., \& Hammer, L. B. (2011). Workplace social support and work-family conflict: A metaanalysis clarifying the influence of general and work-family specific supervisor and organizational support. Personnel Psychology, 64, 289-313.

Love, P. E. D., Goh, Y. M., Hogg, K., Robson, S., \& Irani, Z. (2011). Burnout and sense of coherence among residential real estate brokers. Safety Science, 49(10), 1297-1308. doi:10.1016/j.ssci. 2011.04.009.

Malinauskiene, V., Leisyte, P., Malinauskas, R., \& Malinauskas, R. (2009). Psychosocial job characteristics, social support, and sense of coherence as determinants of mental health among nurses. Medicina (Kaunas), 45(11), 910-917.

Matthews, R. A., Gallus, J. A., \& Henning, R. A. (2011). Participatory ergonomics: Development of an employee assessment questionnaire. Accident Analysis \& Prevention, 34, 360-369.

McKendrick, R., Shaw, T., de Visser, E., Saqer, H., Kidwell, B., \& Parasuraman, R. (2014). Team performance in networked supervisory control of unmanned air vehicles: Effects of automation, working memory, and communication content. Human Factors, 56(3), 463-475.

McCraty, R., Atkinson, M., Lipsenthal, L., \& Arguelles, L. (2009). New hope for correctional officers: An innovative program for reducing stress and health risks. Applied Psychophysiology and Biofeedback, 34(4), 251-272. doi:10.1007/s10484-009-9087-0.

Morgan, P. B. C., Fletcher, D., \& Sarkar, M. (2013). Defining and characterizing team resilience in sport. Psychology of Sport and Exercise, 14, 549-559.

Morse, T., Dussetschleger, J., Warren, N., \& Cherniack, M. (2011). Talking about health: Correction employees' assessments of obstacles to healthy living. Journal of Occupational and Environmental Medicine, 53(9), 1037-1045.
Neveu, J. (2007). Jailed resources: Conservation of resources theory as applied to burnout among prison guards. Journal of Organizational Behavior, 28, 21-42.

NIOSH. (2016). Total Worker Health ${ }^{\circledR}$ program. Retrieved May 23, 2016, from http://www.cdc.gov/niosh/twh/.

Ogińska-Bulik, N. (2005). The role of personal and social resources in preventing adverse health outcomes in employees of uniformed professions. International Journal of Occupational Medicine and Environmental Health, 18(3), 233-240.

Reeves, D. W., Walsh, B. M., Tuller, M. D., \& Magley, V. J. (2012). The positive effects of participative decision making for midlevel correctional management. Criminal Justice and Behavior, 39(10), $1361-1372$.

Robertson, M., Henning, R. A., Warren, N., Nobrega, S., DoveSteinkamp, M., Tibirica, L., et al. (2013). The intervention design and analysis scorecard: A planning tool for participatory design of integrated health and safety interventions in the workplace. Journal of Occupational and Environmental Medicine, 55, S86-S88.

Robertson, M., Henning, R. A., Warren, N., Nobrega, S., DoveSteinkamp, M., Tibirica, L., et al. (2015). Participatory design of integrated safety and health interventions in the workplace: A case study using the Intervention Design and Analysis Scorecard (IDEAS) Tool. International Journal of Human Factors and Ergonomics, 3(3/4), 303-326.

Rothmann, S., Steyn, L. J., \& Mostert, K. (2005). Job stress, sense of coherence and work wellness in an electricity supply organization. South African Journal of Business Management, 36(1), 55-63.

Sagy, S., \& Antonovsky, H. (2000). The development of the sense of coherence: A retrospective study of early life experiences in the family. International Journal of Aging and Human Development, 51(2), 155-166.

Sauter, S. L., Murphy, L. R., \& Hurrell, J. J. (1990). Prevention of work-related psychological disorders. American Psychologist, 45, $1146-1158$.

Schaufeli, W. B., \& Peeters, M. C. W. (2000). Job stress and burnout among correction officers: A literature review. International Journal of Stress Management, 7, 19-48.

Smith, T. J. (2002). Macroergonomics of hazard management. In H. W. Hendrick \& B. M. Kleiner (Eds.), Macroergonomics: Theory, methods, and applications (pp. 199-221). Mahwah, NJ: Lawrence Erlbaum.

Smith, T. J., Henning, R. A., Wade, M. G., \& Fisher, T. (2014). Variability in human performance. Boca Raton, FL: CRC Press.

Smith, T. J., \& Smith, K. U. (1987). Feedback-control mechanisms of human behavior. In G. Salvendy (Ed.), Handbook of human factors (pp. 251-293). New York: Wiley.

Shiu, A. T. (1998). The significance of sense of coherence for the perceptions of task characteristics and stress during interruptions amongst a sample of public health nurses in Hong Kong: Implications for nursing management. Public Health Nursing, 15 (4), 273-280. doi:10.1111/j.1525-1446.1998.tb00350.x.

Söderfeldt, M., Söderfeldt, B., Ohlson, C., Theorell, T., \& Jones, I. (2000). The impact of sense of coherence and high-demand/ low-control job environment on self-reported health, burnout and psycho-physiological stress indicators. Work \& Stress, 14(1), 1-15.

Spinaris, C. G., Denhof, M. D., \& Kellaway, J. A. (2012). Posttraumatic stress disorder in United States corrections professionals: Prevalence and impact on health and functioning. Desert Waters Correctional Outreach Report. Retrieved from http://desertwaters. com/wp-content/uploads/2013/09/PTSD_Prev_in_Corrections_0903-131.pdf.

State of New Jersey, Governor's Task Force on Police Suicide. (2009). New Jersey police suicide task force report (Report No. 2.3.09). 
Retrieved from http://www.state.nj.us/humanservices/dmhs/news/ publications/NJ_police_suicide_TF_rept_jan2009.pdf

Vanndrager, L., \& Koelen, M. (2013). Salutogenesis in the workplace: Building general resistance resources and sense of coherence. In G. F. Bauer \& G. J. Jenny (Eds.), Salutogenic organizations and change: The concepts behind organizational health intervention research (pp. 77-89). Dordrecht: Springer.

Vogt, K., Jenny, G. J., \& Bauer, G. F. (2013). Comprehensibility, manageability and meaningfulness at work: Construct validity of a scale measuring work-related sense of coherence. SA Journal of Industrial Psychology, 39(1), 1-8.

Warren, N., Dussetschleger, J., Punnett, L., \& Cherniack, M. G. (2015). Musculoskeletal disorder symptoms in correction officers: Why do they increase rapidly with job tenure? Human Factors, 57(2), 262-275.

Whitehead, J. T., \& Lindquist, C. A. (1986). Correction officer job burnout: A path model. Journal of Research in Crime and Delinquency, 23, 23-42.

Woodall, J., de Viggiani, N., Dixey, R., \& South, J. (2014). Moving prison health promotion along: Towards an integrative framework for action to develop health promotion and tackle the social determinants of health. Criminal Justice Studies, 27(1), 114-132. doi:10.1080/1478601X.2013.873208.

Zweber, Z. M., Henning, R. A., \& Magley, V. J. (2016). A practical scale for multi-faceted organizational health climate assessment. Journal of Occupational Health Psychology, 21(2), 250-259. 